\title{
Benfotiamine, a synthetic S-acyl thiamine derivative, has different mechanisms of action and a different pharmacological profile than lipid-soluble thiamine disulfide derivatives
}

\author{
Marie-Laure Volvert ${ }^{1}$, Sandrine Seyen ${ }^{1}$, Marie Piette ${ }^{2}$, Brigitte Evrard ${ }^{2}$, \\ Marjorie Gangolf1 ${ }^{1}$, Jean-Christophe Plumier ${ }^{1}$ and Lucien Bettendorff*1
}

Address: ${ }^{1}$ Center for Cellular and Molecular Neurobiology, University of Liège, Avenue de l'Hôpital, 1, 4000 Liège, Belgium and ${ }^{2}$ Laboratory of Pharmaceutical Technology, Department of Pharmacy, University of Liège, Avenue de l'Hôpital, 1, 4000 Liège, Belgium

Email: Marie-Laure Volvert - Marie-Laure.Volvert@student.ulg.ac.be; Sandrine Seyen - Sandrine.Seyen@ulg.ac.be;

Marie Piette - Marie.Piette@ulg.ac.be; Brigitte Evrard - B.Evrard@ulg.ac.be; Marjorie Gangolf - M.Gangolf@student.ulg.ac.be; JeanChristophe Plumier - jc.plumier@ulg.ac.be; Lucien Bettendorff* - L.Bettendorff@ulg.ac.be

* Corresponding author

Published: 12 June 2008

BMC Pharmacology 2008, 8:10 doi:10.1186/147|-2210-8-10
Received: 19 December 2007

Accepted: 12 June 2008

This article is available from: http://www.biomedcentral.com/I47I-22/0/8/10

(C) 2008 Volvert et al; licensee BioMed Central Ltd.

This is an Open Access article distributed under the terms of the Creative Commons Attribution License (http://creativecommons.org/licenses/by/2.0), which permits unrestricted use, distribution, and reproduction in any medium, provided the original work is properly cited.

\begin{abstract}
Background: Lipid-soluble thiamine precursors have a much higher bioavailability than genuine thiamine and therefore are more suitable for therapeutic purposes. Benfotiamine (S-benzoylthiamine Omonophosphate), an amphiphilic S-acyl thiamine derivative, prevents the progression of diabetic complications, probably by increasing tissue levels of thiamine diphosphate and so enhancing transketolase activity. As the brain is particularly sensitive to thiamine deficiency, we wanted to test whether intracellular thiamine and thiamine phosphate levels are increased in the brain after oral benfotiamine administration.

Results: Benfotiamine that is practically insoluble in water, organic solvents or oil was solubilized in 200 $\mathrm{mM}$ hydroxypropyl- $\beta$-cyclodextrin and the mice received a single oral administration of $100 \mathrm{mg} / \mathrm{kg}$. Though thiamine levels rapidly increased in blood and liver to reach a maximum after one or two hours, no significant increase was observed in the brain. When mice received a daily oral administration of benfotiamine for 14 days, thiamine derivatives were increased significantly in the liver but not in the brain, compared to control mice. In addition, incubation of cultured neuroblastoma cells with $10 \mu \mathrm{M}$ benfotiamine did not lead to increased intracellular thiamine levels. Moreover, in thiamine-depleted neuroblastoma cells, intracellular thiamine contents increased more rapidly after addition of thiamine to the culture medium than after addition of benfotiamine for which a lag period was observed.

Conclusion: Our results show that, though benfotiamine strongly increases thiamine levels in blood and liver, it has no significant effect in the brain. This would explain why beneficial effects of benfotiamine have only been observed in peripheral tissues, while sulbutiamine, a lipid-soluble thiamine disulfide derivative, that increases thiamine derivatives in the brain as well as in cultured cells, acts as a central nervous system drug. We propose that benfotiamine only penetrates the cells after dephosphorylation by intestinal alkaline phosphatases. It then enters the bloodstream as S-benzoylthiamine that is converted to thiamine in erythrocytes and in the liver. Benfotiamine, an S-acyl derivative practically insoluble in organic solvents, should therefore be differentiated from truly lipid-soluble thiamine disulfide derivatives (allithiamine and the synthetic sulbutiamine and fursultiamine) with a different mechanism of absorption and different pharmacological properties.
\end{abstract}




\section{Background}

It is well known that thiamine deficiency results in neurological disorders such as beriberi or Wernicke-Korsakoff syndrome [1]. It is generally assumed that the symptoms arise from decreased activity of thiamine diphosphate (ThDP) - dependent enzymes such as transketolase and pyruvate and oxoglutarate dehydrogenases, with subsequent impairment of carbohydrate metabolism in the brain. It is not known to what extent, if any, the decrease in other thiamine derivatives such as thiamine triphosphate (ThTP, [2]) and the newly discovered adenosine thiamine triphosphate (AThTP, [3]) are involved in the appearance of these symptoms.

In a number of diseases, beneficial effects of the administration of free, unphosphorylated thiamine have been reported. Thus, high-dose thiamine therapy reversed the symptoms of Wernicke's encephalopathy [1] and prevented incipient diabetic nephropathy [4] and diabetic dyslipidaemia [5] in experimental diabetes in the rat. Other reports suggested that thiamine may protect against free-radical mediated neurotoxicity [6] and that it may have a cytoprotective effect on cultured neonatal rat cardiomyocytes under hypoxic insult [7]. These protective effects may be due to increased tissue ThDP levels after thiamine treatment, but effects mediated by other phosphorylated thiamine derivatives such as ThTP and AThTP cannot be ruled out.

It is known that free thiamine is transported across plasma membranes by high affinity carriers [8], but the rate of transport is generally slow. For that reason, a variety of lipophilic thiamine derivatives have been synthesized. These compounds can easily diffuse through plasma membranes thus bypassing the rate-limiting transport system required for free thiamine. Once incorporated into the cells, these lipophilic derivatives can be rapidly converted to thiamine through enzymatic or non-enzymatic processes. The first lipophilic thiamine derivative was isolated from garlic (Allium sativum) extracts in the early 1950 s [9]. It is an allyl disulfide derivative called allithiamine (Fig. 1). Since then, several analogs of this molecule were synthesized with the hope that they would be better absorbed and have a higher bioavailability than thiamine hydrochloride or mononitrate $[10,11]$. These lipophilic disulfides are often referred to as "allithiamines", in our opinion an improper denomination as they are synthetic molecules not present in Allium species and do not possess any allyl group.

Presently, two lipophilic disulfide derivatives are used as therapeutic agents: thiamine tetrahydrofurfuryl disulfide ("fursultiamine", Fig. 1) [12] and O-isobutyrylthiamine disulfide ("sulbutiamine", Fig. 1) [13]. Sulbutiamine turned out to be a psychotropic drug prescribed for the symptomatic treatment of functional asthenias [13]. It was found that chronic treatment with sulbutiamine (52 $\mathrm{mg} / \mathrm{kg}$, i.p.) increases thiamine, ThMP, ThDP and ThTP levels in the rat brain as well as in peripheral tissues [14]. Concerning fursultiamine, it is not clear whether it has specific effects on brain function [12] but it exerts a positive inotropic effect in heart muscle [15-17].

S-benzoylthiamine O-monophosphate ("benfotiamine", Fig. 1) is a third derivative with better bioavailability than thiamine. In contrast to the above-mentioned derivatives it is not a disulfide but an S-acyl derivative. It prevents the development and the progression of diabetic complications [18-23]. It was suggested that treatment with benfotiamine blocks three major pathways (the hexosamine pathway, the advanced glycation end product formation pathway and the diacylglycerol-protein kinase pathway) of hyperglycemic damage, probably by removal of glyceraldehyde 3-phosphate and fructose 6-phosphate through activation of the pentose phosphate enzyme transketolase [18]. Other beneficial effects of benfotiamine were the reduction of glucose toxicity $[19,20]$, alleviation of diabetes-induced cerebral oxidative damage [21], acceleration of the healing of ischemic diabetic limbs in mice [22] and rescue of cardiomyocyte contractile dysfunction in experimental diabetes mellitus [23].

Whilst different studies show that administration of benfotiamine leads to higher thiamine blood levels than administration of water-soluble thiamine [10,24-27], practically no information is available concerning its effects on the brain. The aim of the present study was to check whether oral administration of benfotiamine increases the levels of thiamine and its phosphorylated derivatives in the brain of mice.

\section{Results \\ Acute experiment}

As previous studies do not mention the use of a specific carrier for the gavage of mice with benfotiamine $[18,23]$, we first suspended benfotiamine in water and administered it by force-feeding ( $100 \mu \mathrm{l}$ containing a dose equal to $100 \mathrm{mg}$ of benfotiamine per $\mathrm{kg}$ ), using a syringe with a tube that was inserted into the stomach. We sacrificed the animals after 1 hour and we determined thiamine derivatives in the blood. Thiamine levels proved to be highly variable: in some animals thiamine levels were up to 10 times higher than in the controls, while in others they were hardly increased. Benfotiamine is very sparingly soluble in water (at least at $\mathrm{pH}<8.0$ ) and it is possible that in some cases, either most of the material remained attached to the syringe or the force-feeding tube or it was eliminated with the bolus. Therefore, we tested different hydrophobic solvents such as oil (Mineral oil, Sigma M5904) and organic solvents (ethanol, octanol, dimethyl 
Benfotiamine

(S-Benzoylthiamine O-monophosphate)

Allithiamine

(Thiamine allyl disulfide)<smiles>C/C(CCOP(=O)([O-])[O-])=C(\SC(=O)c1ccccc1)N(C=O)Cc1cnc(C)nc1N</smiles>

Fursultiamine
(Thiamine tetrahydrofurfuryl disulfide)

Fursultiamine
(Thiamine tetrahydrofurfuryl disulfide)<smiles>C=CCSS/C(CCO)=C(/C)N(C=O)Cc1cnc(C)nc1N</smiles><smiles>C/C(=C/CCO)N(C=O)Cc1cnc(C)nc1N</smiles>

Sulbutiamine

(O-isobutyrylthiamine disulfide)<smiles>CCOC(=O)C(C)C</smiles><smiles>C/C=C(/C)S[SH]=S</smiles><smiles>CSSCCCOC(=O)C(C)C</smiles>

Figure I

Structures of the S-acyl derivative benfotiamine and the disulfide compounds allithiamine, fursultiamine and sulbutiamine. The thioester bond in benfotiamine is indicated in blue, while the disulfide bond in allithiamine, fursultiamine and sulbutiamine is drawn in red. The allyl group in allithiamine is indicated in green. 
sulfoxide), but no significant solubility was observed. Finally, we obtained a homogenous solution of benfotiamine by forming inclusion complexes in a $200 \mathrm{mM}$ hydroxypropyl- $\beta$-cyclodextrin (HP- $\beta$-CD) solution that was used for force-feeding. This time, the inter-animal variability was reasonable $(25 \%$, S.E.M/mean $\times 100, \mathrm{n}=12)$ and we found that, one hour after the administration, thiamine, ThMP and ThDP levels in the blood were increased by a factor of respectively 822, 14 and 4.7 (Fig. 2). Highly significant increases of free thiamine and ThMP were also observed in the liver, but not in the brain.

\section{Pharmacokinetics}

First, we measured tissue levels of thiamine, ThMP and ThDP for up to 6 hours after a single oral administration of benfotiamine $(100 \mathrm{mg} / \mathrm{kg}$ in a HP- $\beta$-CD solution). In the blood, thiamine levels rapidly increased, reaching a maximum after $120 \mathrm{~min}$ and slowly decreasing thereafter (Fig. 3). ThDP levels steadily increased before reaching a maximum after 4 hours. For ThMP, the highest level was already reached after $30 \mathrm{~min}$ and it slowly decreased during the next hours. In the liver, all derivatives peaked after 1 hour before decreasing to near normal levels after 2 hours. No significant variations were observed in the brain. Total thiamine content (per mg of protein) was about twice higher in the liver than in the brain before benfotiamine administration. One hour after the administration, the ratio was over 10 . However, liver thiamine decreased rather fast after $1-2$ hours. In most samples, we also observed the presence of ThTP and AThTP, but the levels of these compounds in the liver and the brain were not influenced by the treatment (not shown).

\section{Chronic experiment}

As no increase in brain thiamine levels was observed after a single administration of benfotiamine, we decided to test a longer treatment. The animals received a daily oral administration of either $100 \mu \mathrm{l}$ of a solution of benfotiamine $(100 \mathrm{mg} / \mathrm{kg})$ in $200 \mathrm{mM} \mathrm{HP}-\beta-C D$ or $100 \mu \mathrm{l}$ of a $200 \mathrm{mM}$ HP- $\beta-C D$ solution for 14 days and were sacrificed 24 hours later. After treatment with benfotiamine, the levels of free thiamine, ThMP and ThDP were increased in the liver but not in the brain (Fig. 4). Again, the small amounts of ThTP and AThTP found did not depend on the conditions of treatment.

\section{Cell culture experiments}

As treatment with benfotiamine did not yield elevated brain thiamine levels, we wanted to test whether this molecule is able to easily cross cell membranes in cultured cells. We chose mouse neuroblastoma cells (Neuro 2a) as we have previously characterized these cells with respect to thiamine transport $[8,28]$, metabolism [29] and deficiency [30]. The thiamine concentration in the commercial Dulbecco's modified Eagle's medium (DMEM) is 10 $\mu \mathrm{M}$ [8]. Therefore, once the cells were nearly confluent, DMEM was replaced by a saline containing $10 \mu \mathrm{M}$ of either thiamine or benfotiamine. After incubation for up to $4 \mathrm{~h}$ at $37^{\circ} \mathrm{C}$, the thiamine content of the cells was determined. We did not observe any increase in intracellular thiamine after incubation with benfotiamine and there were no significant differences between the thiamine and benfotiamine groups (Fig. 5). This is in sharp contrast with previous experiments where incubation of the same cell line with $10 \mu \mathrm{M}$ sulbutiamine under the same conditions led to a 10-fold increase in intracellular free (unphosphorylated) thiamine within 2 hours [29].

As mentioned above, the thiamine concentration in most commercial culture media is about $10 \mu \mathrm{M}$, one or two orders of magnitude higher than the $K_{\mathrm{m}}$ for the high affinity thiamine transport present in most cells $[8,28,29]$. Cells grown under those conditions are thus saturated with thiamine. Therefore, we wanted to test whether benfotiamine had any effect on intracellular thiamine levels in Neuro 2a cells previously thiamine-depleted. The cells were grown for 8 days in a medium containing about 7 $\mathrm{nM}$ thiamine. Then either benfotiamine $(1 \mu \mathrm{M})$ or thiamine $(1 \mu \mathrm{M})$ was added (Fig. 6$)$. After 2 hours in the presence of thiamine, intracellular thiamine already reached a maximum, while with benfotiamine an important lag period was observed. This experiment confirms that thiamine enters Neuro 2a cells more rapidly than benfotiamine. The lag period can be explained if benfotiamine is first dephosphorylated by ecto-phosphatases to the lipidsoluble S-benzoylthiamine that can then enter the cells (see below).

\section{Discussion}

\section{Mechanism of action of benfotiamine}

In 1961, Wada et al. reported the physicochemical properties of benfotiamine and its possible use as a therapeutic agent [31]. Benfotiamine is more easily absorbed by the body and oral administration results in higher thiamine and ThDP blood levels in animals than an equivalent dose of thiamine. A few years, later Shindo and coworkers [32-35] studied in more detail the mechanism of absorption and the metabolic fate of benfotiamine in animal tissues. Their results suggested that benfotiamine (given orally) is first dephosphorylated to S-benzoylthiamine by the ecto-alkaline phosphatase present in the brush borders of intestinal mucosal cells. The more lipophilic Sbenzoylthiamine then diffuses through the membranes of intestinal and endothelial cells and appears in the venous mesenteric blood. A significant part of S-benzoylthiamine is captured by erythrocytes [34] and converted to free thiamine through a slow non-enzymatic transfer of the Sbenzoyl group to SH groups of glutathione. In the liver, the remainder can be enzymatically hydrolyzed to thiamine and benzoic acid by thioesterases present in the 

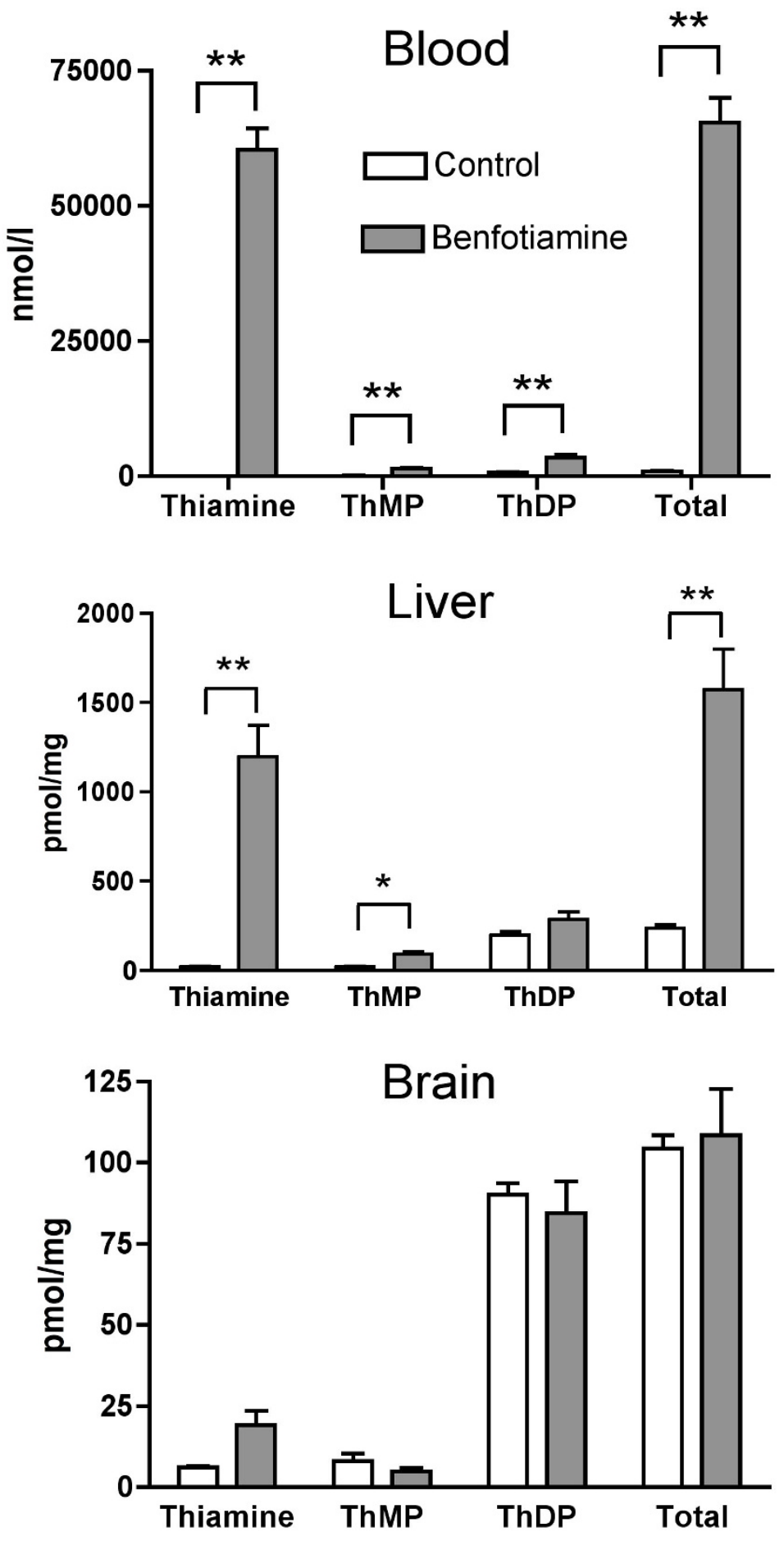

Figure 2

Contents of thiamine, ThMP, ThDP and total thiamine in the blood, the liver and the brain of mice (strain sv I 29) I hour after a single oral administration of $100 \mu \mathrm{l}$ of $200 \mathrm{mM} \mathrm{HP-b}-\mathrm{CD}$ or benfotiamine (I $00 \mathrm{mg} / \mathrm{kg}$ ) in approximately $100 \mu \mathrm{l}$ of a $200 \mathrm{mM}$ HP-b-CD solution. The data were analyzed by MANOVA (Wilk's Lambda, $\mathrm{P}=$ $0.0002,0.0145$ and 0.27 for blood, liver and brain respectively) followed by ANOVA for each thiamine compound (*, $P<0.05$; **, $\mathrm{p}<0.01$ ). The results are expressed as mean \pm SEM for 4 animals in each group. 

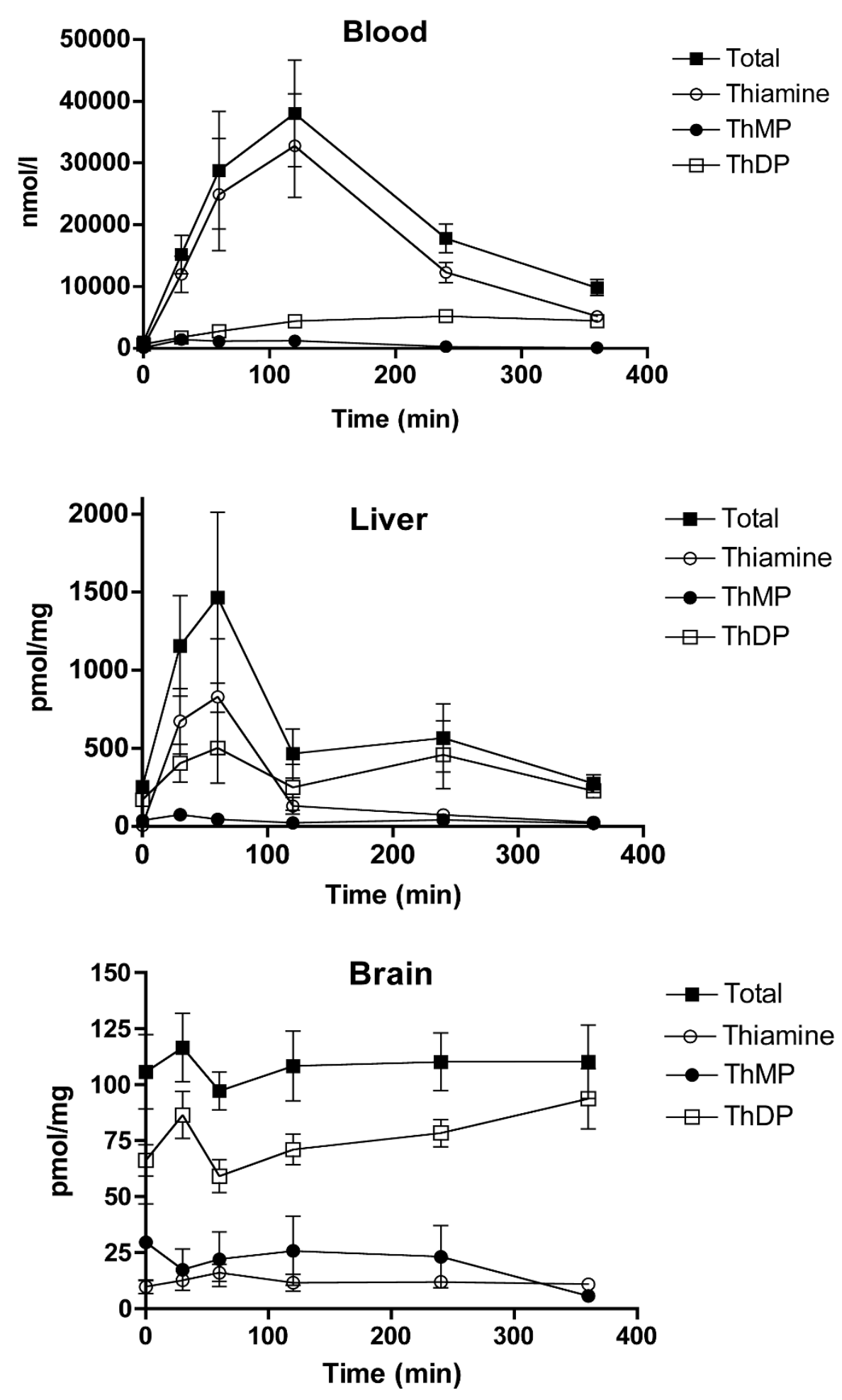

Figure 3

Time-dependent tissue content of thiamine derivatives after a single oral administration of benfotiamine ( 100 $\mathrm{mg} / \mathrm{kg}$ ) in approximately $100 \mu \mathrm{l}$ of a $200 \mathrm{mM}$ HP- $\beta-C D$ solution in mice (strain C57B6). The results are expressed as mean \pm SEM for $6-7$ animals for each time point. 

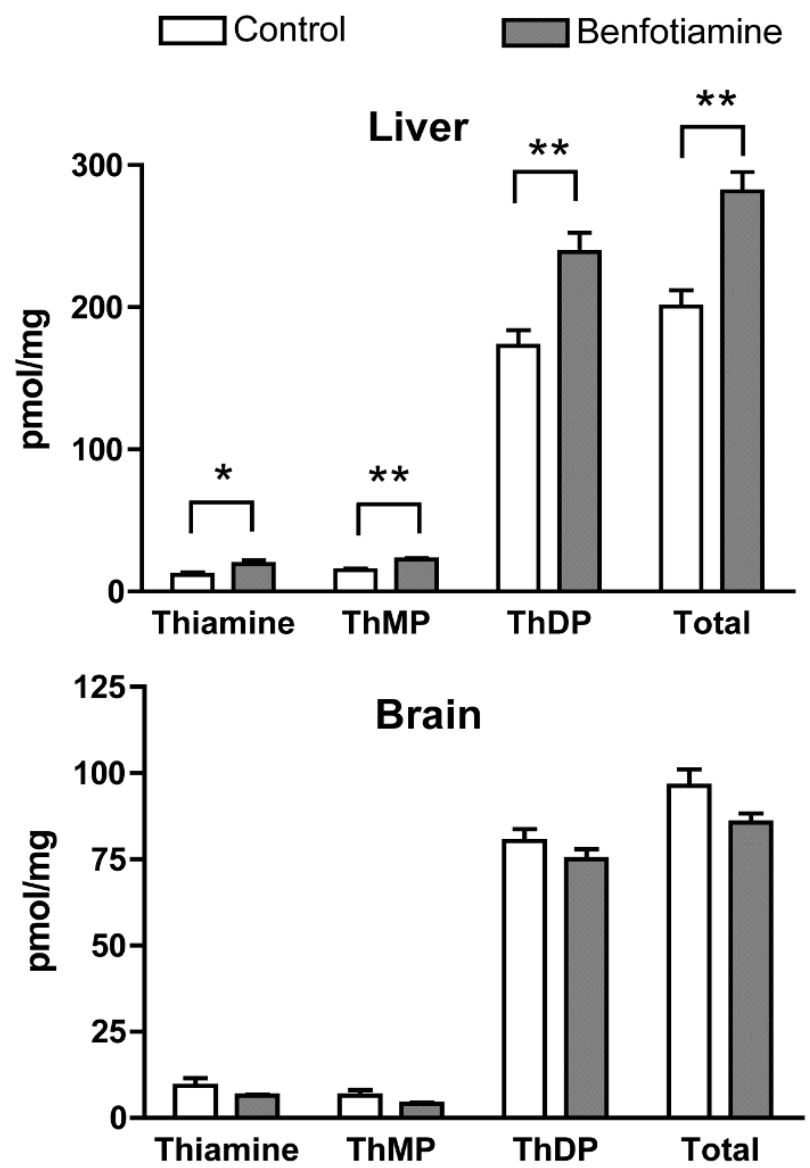

Figure 4

Contents of thiamine, ThMP, ThDP and total thiamine in the liver and the brain of mice (strain sv I 29) after daily oral administration of $200 \mathrm{mM}$ HP- $\beta$-CD (8 animals) or benfotiamine ( $100 \mathrm{mg} / \mathrm{kg})$ in approximately $100 \mu$ l of a 200 HP- $\beta$-CD solution ( 10 animals) for 14 days. The data (mean \pm SEM) were analyzed by MANOVA (Liver : Wilk's Lambda $=0.24, p=0.006 \mathrm{I}$; Brain : Wilk's Lambda $=0.779, p=0.48$ ) followed by an ANOVA for each thiamine compound $(*, p<0.05$; **, $p<0.0$ I).

hepatocytes. On the other hand, thiamine disulfide derivatives require a reduction either enzymatically in the liver by glutathione or non enzymatically in blood by glutathione and possibly other substrates [36]. In the present work, we show that after oral administration of benfotiamine to mice, free thiamine appears in the liver at a fast rate, reaching a maximum after one hour, while in the blood the maximum is reached only after two hours (Fig. 3 ). We therefore propose that most of the S-benzoylthiamine present in the mesenteric blood is captured by the liver and transformed into thiamine. The excess thiamine formed is then rapidly released into the blood stream, as shown by the fast decrease of thiamine content in the liver after $1-2$ hours (Fig. 3). Such a scheme is in agreement with an earlier report that, after infusion of benfotiamine to the small intestine of the dog, mainly free thiamine (not S-benzoylthiamine) was detected in the carotid blood [35]. Free thiamine is not lipophilic and cannot cross the blood-brain barrier by simple diffusion. Transport of blood thiamine to the brain parenchyma is carriermediated and it is a slow process [37]. In the present study, we find that blood thiamine concentration in the control animals is approximately $0.4 \mu \mathrm{mol} / \mathrm{l}$, a value close to the half-maximal activation constant for the high affinity transport of thiamine across the blood-brain barrier [8]. Though a second, low affinity, component of thiamine transport was also observed, its contribution was small. Thus, raising free blood thiamine concentrations does not necessarily lead to an important increase in thiamine transport across the blood-brain barrier. It is therefore not very surprising that benfotiamine administration does not lead to an increase in total thiamine content of the brain (Figs 2, 3 and 4). It should be noted however that one study showed a 90\% increase of ThDP levels in the brains of rats that received a dose of $1645 \mathrm{mg}$ of benfotiamine/kg of diet for 6 months [27].

\section{Differences between benfotiamine and lipophilic thiamine disulfide derivatives}

Wada et al. already noted that benfotiamine was sparingly soluble in organic solvents such as benzene, chloroform and methanol, but was readily soluble in aqueous media at $\mathrm{pH} \geq 8.0$ [31]. This is not surprising as the phosphoryl group of benfotiamine has two negative charges at alkaline $\mathrm{pH}$. Here, we confirm that benfotiamine is sparingly soluble in water at $\mathrm{pH} \leq 7.0$ and cannot be dissolved in octanol or oils. Thus benfotiamine should not be classified as a "lipophilic" compound as many authors still do $[10,24,25,38]$. Indeed, benfotiamine appears unable to diffuse across cell membranes. We have shown here that intracellular thiamine content is not increased in cultured neuroblastoma incubated in the presence of $10 \mu \mathrm{M}$ benfotiamine, while it was increased ten-fold after incubation with $10 \mu \mathrm{M}$ sulbutiamine [29]. Moreover, after a chronic treatment of rats with sulbutiamine intracellular thiamine derivatives were increased by respectively 250\% (thiamine), 40\% (ThMP), 25\% (ThDP) and 40\% (ThTP) [14].

This is in apparent contradiction with results obtained with cultured cells of endothelial origin [18-20,39], showing that benfotiamine is able to counteract glucose toxicity in these cells by increasing transketolase activity. However, the benfotiamine concentrations used were 50 $-100 \mu \mathrm{M}$, much higher than in our study. Hammes et al. even report that there was no effect on transketolase activity in cultured endothelial cells at 10 or $25 \mu \mathrm{M}$ [18]. In any event, this is no proof that benfotiamine is able to cross the membranes: indeed, cultured endothelial cells seem to possess an ecto-alkaline phosphatase [40]. It is there- 


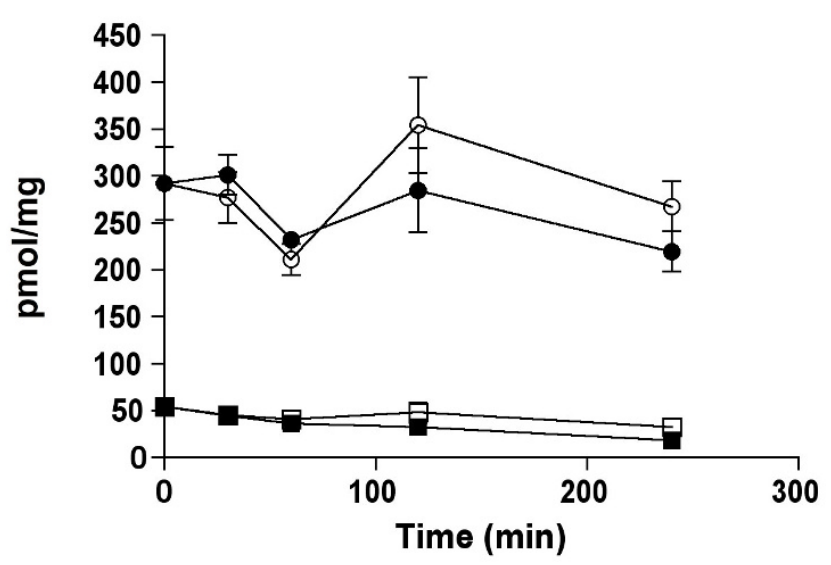

Figure 5

Contents of total $(\bigcirc, 0)$ and unphosphorylated $(\square$, D) thiamine during incubation of Neuro2a cells in the presence of $10 \mu \mathrm{M}$ thiamine $(\bigcirc, \square)$ or benfotiamine

$(\mathbf{O}, \square)$. The data are expressed as mean \pm SEM for 4 experiments.

fore likely that, in these cells, the added benfotiamine is at least partially dephosphorylated to S-benzoylthiamine that can enter the cells as in the case of the intestinal mucosa. The slow dephosphorylation to S-benzoylthiamine might also explain the lag period observed between the addition of benfotiamine to thiamine-depleted Neuro $2 a$ cells and the increase in intracellular thiamine derivatives (Fig. 6). In erythrocytes, it was shown that fursultiamine, a lipophilic disulfide, is rapidly incorporated into the cells while benfotiamine is not [41]. Taken together, these results strongly suggest that benfotiamine is unable to cross plasma membranes unless it is dephosphorylated.

\section{Benfotiamine and sulbutiamine have different pharmacological profiles}

Since the discovery of allithiamine [9], a number of derivatives were synthesized. These showed higher bioavailability than thiamine hydrochloride or mononitrate. Lipidsoluble thiamine derivatives were developed mainly in Japan for the treatment of beriberi. It was therefore surprising that sulbutiamine appeared to exert specific effects on brain function. Indeed, it seems to improve memory in rodents $[42,43]$ and, in humans, it seems to be beneficial against functional asthenias $[13,44,45]$. These effects have not been reported with thiamine. This difference might be explained if we assume that sulbutiamine (or its degradation product thiamine disulfide) can cross the bloodbrain barrier and have specific actions in neurons. However, there is so far no direct evidence that untransformed sulbutiamine is indeed found in the brain. Concerning benfotiamine, there is no evidence that it has any specific

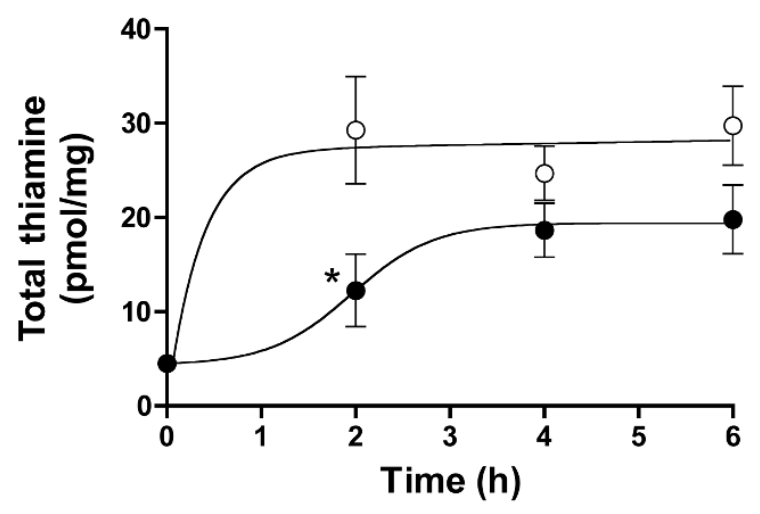

Figure 6

Effect of thiamine and benfotiamine on the total thiamine content in thiamine-depleted Neuro 2 a cells.

The cells were grown for 8 days in thiamine deficient DMEM medium containing $5 \%$ fetal calf serum, before addition of thiamine $(\mathrm{I} \mu \mathrm{M}, \mathrm{O})$ or benfotiamine $(\mathrm{I} \mu \mathrm{M}, \mathrm{O})$ and intracellular thiamine derivatives were determined at the times indicated. The data (mean $\pm \mathrm{SEM}, \mathrm{n}=3$ ) were analyzed by two-way ANOVA followed by the Bonferroni post-test for comparison of the benfotiamine and the thiamine groups at different times $(*, p<0.05)$.

effect on the central nervous system, but during the last few years, there was considerable interest in the therapeutic potential of benfotiamine in peripheral tissues. Indeed, it was found effective for the protection of diabetic complications such as diabetic neuropathy [18-23] and alcoholic neuropathy [46]. Our results are in agreement with the different pharmacological profiles of sulbutiamine and benfotiamine. We previously found that sulbutiamine treatment significantly increases thiamine, ThMP, ThDP and ThTP content of rat brain [14], while the present results show that benfotiamine, at a twice higher dose, is unable to raise the levels of intracerebral thiamine phosphate derivatives (Figs 2, 3 and 4). This is in agreement with a previous study showing that after administration of ${ }^{3} \mathrm{H}$-benfotiamine, liver and kidney were labeled to a higher degree than brain and muscles [47], but this study did not make a difference between benfotiamine and its labeled metabolites and degradation products. Furthermore our results on cultured neuroblastoma cells show that benfotiamine, in contrast to sulbutiamine, does not easily cross cell membranes (Figs 5 and 6). It would therefore be interesting to test whether a thiamine disulfide compound such as sulbutiamine or fursultiamine, would not be more efficient and act at lower concentrations than benfotiamine in counteracting diabetic complications. A recent study has shown that, at high concentration $(300 \mu \mathrm{M})$, benfotiamine exerts a direct antioxidant effects in three different kidney cell lines, 
independently of its transformation in thiamine and increased transketolase activity [48]. It is however not yet clear to what extend, if any, this may be involved in the improvement of diabetic complications.

\section{Conclusion}

Our results show that oral administration of benfotiamine leads to significant increases in thiamine, ThMP and ThDP levels in blood, liver but not in the brain. This difference is in agreement with the known pharmacological profile of benfotiamine, i.e. the beneficial effects of the drug concern peripheral tissues but not the central nervous system. Like disulfide derivatives, benfotiamine may be useful for the treatment of acute peripheral syndromes of thiamine deficiency because it is better absorbed than thiamine, but in contrast to sulbutiamine, it seems to be devoid of specific effects on brain function. On the other hand, sulbutiamine should be much more efficient than benfotiamine in the treatment of Wernicke-Korsakoff syndrome. Physico-chemical data as well as studies with isolated cells strongly suggest that, in contrast to disulfide derivatives, benfotiamine is not a lipophilic compound and is unable to diffuse through cell membranes unless it is first dephosphorylated by ecto-alkaline phosphatases. Finally, it seems important to us that, because of different chemical, metabolic and pharmacological properties, a clear distinction should be made between lipophilic thiamine disulfides (derived from allithiamine) and S-acyl derivatives such as benfotiamine.

\section{Methods}

\section{Administration of benfotiamine}

Benfotiamine (Sigma-Aldrich) was dissolved in a $200 \mathrm{mM}$ solution of hydroxypropyl- $\beta$-cyclodextrin (HP- $\beta-C D$, Roquette, Lestrem, France) at a concentration of $25 \mathrm{mg} /$ $\mathrm{ml}$. The solution was homogenized at $4{ }^{\circ} \mathrm{C}$. The mice were force-fed with a dose of $100 \mathrm{mg}$ benfotiamine $/ \mathrm{kg}$ in approximately $100 \mu \mathrm{l}$ using a syringe prolonged by a flexible tube that was inserted into the stomach. The mice strains (male, 8 weeks old) were either C57B6 or Sv129. Control animals received an oral administration of $100 \mu \mathrm{l}$ HP- $\beta$-CD solution $(200 \mathrm{mM})$ without benfotiamine. The local committee for animal care and use approved all animal experiments.

\section{Sample preparation and determination of thiamine derivatives by HPLC}

The mice were anesthetized with isoflurane and the forebrain and the liver were collected. For collecting blood samples, the animals were anesthetized with isoflurane and heparin sulfate sodium salt (5000 I.U./ml, Leo Pharma, Wilrijk, Belgium) was injected directly into the heart $(50 \mu \mathrm{l})$. Tissues were stored at $-80^{\circ} \mathrm{C}$ until sample preparation. About $50 \mathrm{mg}$ of tissue were homogenized in $500 \mu \mathrm{l}$ trichloroacetic acid (TCA, $12 \% \mathrm{w} / \mathrm{v}$ ) in a glass-glass homogenizer. The homogenates were centrifuged (5000 $\times$ $\mathrm{g}, 10 \mathrm{~min}, 4^{\circ} \mathrm{C}$ ) and the TCA was extracted from the supernatant with $3 \times 1.5 \mathrm{ml}$ diethylether. The samples were kept at $-20^{\circ} \mathrm{C}$ until use. HPLC analysis was performed exactly as previously described [49]. Protein concentrations were determined by the method of Peterson [50].

\section{Cell culture}

Mouse neuroblastoma cells (Neuro 2a) were grown as previously described in $100 \mathrm{~mm}$ Petri dishes containing $10 \mathrm{ml}$ Dulbecco's modified Eagle's medium (DMEM, N.V. Invitrogen SA, Merelbeke, Belgium), supplemented with $10 \%$ fetal calf serum [29]. When the dishes were nearly confluent (5 - $10 \mathrm{mg}$ of protein/dish), the culture medium was replaced by $10 \mathrm{ml}$ of saline $(145 \mathrm{mM} \mathrm{NaCl}$, $5 \mathrm{mM} \mathrm{KCl}, 1 \mathrm{mM} \mathrm{MgCl}_{2}, 1 \mathrm{mM} \mathrm{CaCl}_{2}, 10 \mathrm{mM}$ glucose, $10^{2}$ $\mathrm{mM}$ Hepes-Tris, $\mathrm{pH}$ 7.3) containing either $10 \mu \mathrm{M}$ benfotiamine or $10 \mu \mathrm{M}$ thiamine. A $10 \mathrm{mM}$ stock solution of benfotiamine was prepared in a mixture of ethanol (50\%) and water. $\mathrm{HCl}$ was added until a homogenous solution was obtained. After incubation $\left(0\right.$ to 4 hours at $\left.37^{\circ} \mathrm{C}\right)$, the cells were centrifuged $(2000 \times \mathrm{g}, 2 \mathrm{~min})$ and the pellet was suspended in $500 \mu \mathrm{l}$ TCA (12\%). The proteins were sedimented $(5000 \times \mathrm{g}, 3 \mathrm{~min})$ and thiamine derivatives were determined in the supernatant after extraction of TCA by diethylether as described above.

Neuro 2a cells were thiamine-depleted as previously described $[8,30]$. Briefly the cells were grown in DMEM medium devoid of thiamine (Invitrogen). The concentration of fetal calf serum that contains about $14 \mathrm{nM}$ of thiamine, was reduced to $5 \%$. The medium was replaced every 2 days and the cells subcultured every 4 days. After 8 days, either thiamine $(1 \mu \mathrm{M})$ or benfotiamine $(1 \mu \mathrm{M})$ were added and the intracellular thiamine levels were determined as a function of time (up to $6 \mathrm{~h}$ ) as described above.

\section{Statistics}

Data were analyzed by multivariate analyses of variance (MANOVA), followed by ANOVA for follow-up comparisons or two-way ANOVA followed by the Bonferroni posttest.

\section{Abbreviations}

AThTP: adenosine thiamine triphosphate; DMEM: Dulbecco's modified Eagle's medium; HP- $\beta$-CD: hydroxypropyl- $\beta$-cyclodextrin; TCA: trichloroacetic acid; ThMP: thiamine monophosphate; ThDP: thiamine diphosphate; ThTP: thiamine triphosphate.

\section{Competing interests}

The authors declare that they have no competing interests. 


\section{Authors' contributions}

$\mathrm{M}-\mathrm{LV}$ and SS performed most of the experimental part of the work. MG contributed to the experimental part. MP and BE suggested to formulate benfotiamine with cyclodextrins and made the initial solubility tests. J-CP and LB were the project leaders and participated in the design. LB wrote the final manuscript. All authors read and approved the final manuscript.

\section{Acknowledgements}

This work was supported by the Fonds de la Recherche Fondamentale Collective (Belgium). LB is Research Director at the Fonds de la Recherche Scientifique-FNRS. MLV and MG are the recipients of a fellowship from the Fonds pour la Formation à la Recherche dans I'Industrie et dans I'Agriculture (FRIA). The authors wish to thank Dr. Pierre Wins for many helpful discussions and reading the manuscript.

\section{References}

I. Victor M, Adams RD, Collins GH: The Wernicke-Korsakoff syndrome. A clinical and pathological study of 245 patients, 82 with post-mortem examinations. Contemp Neurol Ser 197I, 7:1-206.

2. Makarchikov AF, Lakaye B, Gulyai IE, Czerniecki J, Coumans B, Wins $P$, Grisar T, Bettendorff $L$ : Thiamine triphosphate and thiamine triphosphatase activities: from bacteria to mammals. Cell Mol Life Sci 2003, 60:1477-I488.

3. Bettendorff L, Wirtzfeld B, Makarchikov AF, Mazzucchelli G, Frédérich M, Gigliobianco T, Gangolf M, De Pauw E, Angenot L, Wins $P$ : Discovery of a natural thiamine adenine nucleotide. Nat Chem Biol 2007, 3:21।-2I2.

4. Babaei-Jadidi R, Karachalias N, Ahmed N, Battah S, Thornalley PJ: Prevention of incipient diabetic nephropathy by high-dose thiamine and benfotiamine. Diabetes 2003, 52:21 10-2I20.

5. Babaei-Jadidi R, Karachalias N, Kupich C, Ahmed N, Thornalley PJ: High-dose thiamine therapy counters dyslipidaemia in streptozotocin-induced diabetic rats. Diabetologia 2004, 47:2235-2246.

6. Sheline CT, Wei L: Free radical-mediated neurotoxicity may be caused by inhibition of mitochondrial dehydrogenases in vitro and in vivo. Neuroscience 2006, 140:235-246.

7. Shin BH, Choi SH, Cho EY, Shin MJ, Hwang KC, Cho HK, Chung JH, Jang $Y$ : Thiamine attenuates hypoxia-induced cell death in cultured neonatal rat cardiomyocytes. Mol Cells 2004, 18:133-140.

8. Bettendorff $L$, Wins $P$ : Mechanism of thiamine transport in neuroblastoma cells. Inhibition of a high affinity carrier by sodium channel activators and dependence of thiamine uptake on membrane potential and intracellular ATP. J Biol Chem 1994, 269:14379-14385.

9. Fujiwara M, Watanabe $H$, Katsui K: Allithiamine, a newly found derivative of vitamin BI. J Biochem 1954, 41:29-39.

10. Greb A, Bitsch R: Comparative bioavailability of various thiamine derivatives after oral administration. Int J Clin Pharmacol Ther 1998, 36:216-221.

II. Lonsdale D: A Review of the Biochemistry, Metabolism and Clinical Benefits of Thiamin(e) and Its Derivatives. Evid Based Complement Alternat Med 2006, 3:49-59.

12. Lonsdale D: Thiamine tetrahydrofurfuryl disulfide: a little known therapeutic agent. Med Sci Monit 2004, I 0:RAI 99-203.

13. Van Reeth O: Pharmacologic and therapeutic features of sulbutiamine. Drugs Today 1999, 35:187-192.

14. Bettendorff L, Weekers L, Wins P, Schoffeniels E: Injection of sulbutiamine induces an increase in thiamine triphosphate in rat tissues. Biochem Pharmacol 1990, 40:2557-2560.

15. Shinozaki H: Cardiac action of thiamine derivatives in guinea pig atria. J Nutr Sci Vitaminol 1976, 22:29-34.

16. Houzen $H$, Kanno $M$ : Thiamine and its derivatives inhibit delayed rectifier potassium channels of rat cultured cortical neurons. Neuropharmacology 1998, 37:313-322.

17. Tohse N, Houzen H, Kanno M: Inhibition of the delayed rectifier $\mathrm{K}$ current in guinea-pig cardiomyocytes by thiamine tetrahy- drofurfuryl disulfide. Naunyn-Schmiedeberg's Arch Pharmacol 1998 , 357:540-547.

18. Hammes HP, Du X, Edelstein D, Taguchi T, Matsumura T, Ju Q, Lin J, Bierhaus A, Nawroth P, Hannak D, et al:: Benfotiamine blocks three major pathways of hyperglycemic damage and prevents experimental diabetic retinopathy. Nat Med 2003, 9:294-299.

19. Berrone E, Beltramo E, Solimine C, Ape AU, Porta M: Regulation of intracellular glucose and polyol pathway by thiamine and benfotiamine in vascular cells cultured in high glucose. J Biol Chem 2006, 28I:9307-9313.

20. Marchetti V, Menghini R, Rizza S, Vivanti A, Feccia T, Lauro D, Fukamizu A, Lauro R, Federici M: Benfotiamine counteracts glucose toxicity effects on endothelial progenitor cell differentiation via Akt/FoxO signaling. Diabetes 2006, 55:223 I-2237.

21. Wu S, Ren J: Benfotiamine alleviates diabetes-induced cerebral oxidative damage independent of advanced glycation end-product, tissue factor and TNF-alpha. Neurosci Lett 2006, 394: $158-162$.

22. Gadau S, Emanueli C, Van Linthout S, Graiani G, Todaro M, Meloni M, Campesi I, Invernici G, Spillmann F, Ward K, et al.: Benfotiamine accelerates the healing of ischaemic diabetic limbs in mice through protein kinase B/Akt-mediated potentiation of angiogenesis and inhibition of apoptosis. Diabetologia 2006, 49:405-420.

23. Ceylan-Isik AF, Wu S, Li Q, Li SY, Ren J: High-Dose Benfotiamine Rescues Cardiomyocyte Contractile Dysfunction in Streptozotocin-Induced Diabetes Mellitus. J Appl Physiol 2006, 100:I50-I56.

24. Bitsch R, Wolf M, Moller J, Heuzeroth L, Gruneklee D: Bioavailability assessment of the lipophilic benfotiamine as compared to a water-soluble thiamin derivative. Ann Nutr Metab 1991, 35:292-296

25. Loew D: Pharmacokinetics of thiamine derivatives especially of benfotiamine. Int J Clin Pharmacol Ther 1996, 34:47-50.

26. Schreeb KH, Freudenthaler S, Vormfelde SV, Gundert-Remy U, Gleiter $\mathrm{CH}$ : Comparative bioavailability of two vitamin B I preparations: benfotiamine and thiamine mononitrate. Eur J Clin Pharmacol 1997, 52:319-320.

27. Netzel M, Ziems M, Jung KH, Noll E, Borsch C, Bitsch I: Effect of high-dosed thiamine hydrochloride and S-benzoyl-thiamineO-monophosphate on thiamine-status after chronic ethanol administration. Biofactors 2000, I I:I I I-I I3.

28. Szyniarowski P, Bettendorff L, Schweingruber ME: The antitrypanosomal drug melarsoprol competitively inhibits thiamin uptake in mouse neuroblastoma cells. Cell Biol Toxicol 2006, 22: 183-187.

29. Bettendorff $L$ : The compartmentation of phosphorylated thiamine derivatives in cultured neuroblastoma cells. Biochim Biophys Acta 1994, I 222:7-14.

30. Bettendorff L, Goessens G, Sluse F, Wins P, Bureau M, Laschet J, Grisar T: Thiamine deficiency in cultured neuroblastoma cells: effect on mitochondrial function and peripheral benzodiazepine receptors. J Neurochem 1995, 64:2013-202I.

31. Wada T, Takagi H, Minakami H, Hamanaka W, Okamoto K, Ito A, Sahashi Y: A new thiamine derivative, S-benzoylthiamine $\mathbf{O}$ monophosphate. Science 1961, 134:195-196.

32. Yamazaki M: Studies on the absorption of S-benzoylthiamine O-monophosphate: (I) Metabolism in tissue homogenates. Vitamins 1968, 38:12-20.

33. Mizuhira B, Uchida K, Totsu J, Shindo H: Studies on the absorption of S-benzoylthiamine O-monophosphate: (IV) Electronmicroscopic autoradiography on the intestinal absorption of S-benzoyl-3H O-monophosphate in rat. Vitamins 1968, 38:334-336.

34. Shindo $H$, Okamoto $K$, Tohtsu J, Takahashi I: Studies on the absorption of S-benzoylthiamine O-monophosphate: (II) Permeability to red cell membranes. Vitamins 1968, 38:21-29.

35. Shindo H, Okamoto K, Wada T, Koike H, Kumakura S: Studies on the absorption of S-benzoylthiamine O-monophosphate: (III) Mechanism of the intestinal absorption. Vitamins 1968, 38:30-37.

36. Kohno K, Noda K, Mizobe M, Utsumi I: Enzymatic reduction of disulfide-type thiamine derivatives. Biochem Pharmacol 1969, 18:1685-1692. 
37. Greenwood J, Love ER, Pratt OE: Kinetics of thiamine transport across the blood-brain barrier in the rat. J Physiol 1982, 327:95-103.

38. Ziems M, Netzel M, Bitsch I: Biokinetic parameters and metabolism of S-benzoylthiamine-O-monophosphate. Biofactors 2000, II:109-110.

39. Beltramo E, Berrone E, Buttiglieri S, Porta M: Thiamine and benfotiamine prevent increased apoptosis in endothelial cells and pericytes cultured in high glucose. Diabetes Metab Res Rev 2004, 20:330-336.

40. Kapojos JJ, Poelstra K, Borghuis T, Berg A Van Den, Baelde HJ, Klok PA, Bakker WW: Induction of glomerular alkaline phosphatase after challenge with lipopolysaccharide. Int J Exp Pathol 2003, 84: I35-I44.

4I. Itokawa Y, Nishino K, Igarashi S: Evaluation of thiamin derivatives: human bioavailability, uptake by human blood cells, and conversion to thiamin by rat liver homogenate. Vitamins 1992, 66:35-42.

42. Micheau J, Durkin TP, Destrade C, Rolland Y, Jaffard R: Chronic administration of sulbutiamine improves long term memory formation in mice: possible cholinergic mediation. Pharmacol Biochem Behav 1985, 23:195-198.

43. Bizot JC, Herpin A, Pothion S, Pirot S, Trovero F, Ollat H: Chronic treatment with sulbutiamine improves memory in an object recognition task and reduces some amnesic effects of dizocilpine in a spatial delayed-non-match-to-sample task. Prog Neuropsychopharmacol Biol Psychiatry 2005, 29:928-935.

44. Trovero F, Gobbi M, Weil-Fuggaza J, Besson MJ, Brochet D, Pirot S: Evidence for a modulatory effect of sulbutiamine on glutamatergic and dopaminergic cortical transmissions in the rat brain. Neurosci Lett 2000, 292:49-53.

45. Douzenis A, Michopoulos I, Lykouras L: Sulbutiamine, an 'innocent' over the counter drug, interferes with therapeutic outcome of bipolar disorder. World I Biol Psychiatry 2006, 7: I83-I85.

46. Woelk $H$, Lehrl S, Bitsch R, Kopcke W: Benfotiamine in treatment of alcoholic polyneuropathy: an 8-week randomized controlled study (BAP I Study). Alcohol Alcohol I998, 33:63 I-638.

47. Hilbig R, Rahmann H: Comparative autoradiographic investigations on the tissue distribution of benfotiamine versus thiamine in mice. Arzneimittelforschung 1998, 48:46I-468.

48. Schmid U, Stopper H, Heidland A, Schupp N: Benfotiamine exhibits direct antioxidative capacity and prevents induction of DNA damage in vitro. Diabetes Metab Res Rev 2008 in press.

49. Bettendorff L, Peeters M, Jouan C, Wins P, Schoffeniels E: Determination of thiamin and its phosphate esters in cultured neurons and astrocytes using an ion-pair reversed-phase highperformance liquid chromatographic method. Anal Biochem 1991, 198:52-59.

50. Peterson GL: A simplification of the protein assay method of Lowry et al. which is more generally applicable. Anal Biochem 1977, 83:346-356.

Publish with Bio Med Central and every scientist can read your work free of charge

"BioMed Central will be the most significant development for disseminating the results of biomedical research in our lifetime. "

Sir Paul Nurse, Cancer Research UK

Your research papers will be:

- available free of charge to the entire biomedical community

- peer reviewed and published immediately upon acceptance

- cited in PubMed and archived on PubMed Central

- yours - you keep the copyright

Submit your manuscript here:

http://www.biomedcentral.com/info/publishing_adv.asp
BioMedcentral 